\title{
Evaluating Genetic Parameters and Combining Ability of Starch Viscosity Parameters in Rice Cultivars (Oryza sativa L.)
}

\author{
Alireza Haghighi Hasanalideh ${ }^{1, a, *}$, Mehrzad Allahgholipour ${ }^{2, b}$, Ezatollah Farshadfar $^{1, c}$ \\ ${ }^{1}$ Department of Production Engineering and Plant Genetics, Faculty of Agricultural Sciences and Engineering, Campus of Agriculture and \\ Natural Resources, Razi University, Kermanshah, Iran. \\ ${ }^{2}$ Department of Seed Improvement, Rice Research Institute of Iran, Agricultural Research, Education and Extension Organization \\ (AREEO), Rasht, Iran. \\ *Corresponding author
}

\begin{tabular}{|c|c|}
\hline A R T I C L E I N F O & A B S T R A C T \\
\hline $\begin{array}{l}\text { Keywords: } \\
\text { RVA parameters } \\
\text { Combining ability } \\
\text { Gene action } \\
\text { Diallel mating } \\
\text { Rice }\end{array}$ & $\begin{array}{l}\text { This study was undertaken to assess the combining ability of } 6 \text { rice varieties, for viscosity parameters } \\
\text { and determining gene action controlling Rapid Visco Analyser (RVA) characters. F2 progenies } \\
\text { derived from a } 6 \times 6 \text { half diallel mating design with their parents were grown in a randomized } \\
\text { complete block design with three replications at the research farm of Rice Research Institute of Iran } \\
\text { (RRII) in } 2015 \text {. The diallel analysis by Griffing`s method indicated the involvement of additive and } \\
\text { non-additive gene actions controlling RVA traits. For traits PV and FV RI18447-2 and IR50 were } \\
\text { the best combiners for increasing and decreasing, respectively. Deylamani and IR50 were the best } \\
\text { combiners for increasing and decreasing BV, respectively. Beside, due to more portion of non- } \\
\text { additive gene action in controlling trait SV, The Gilaneh } \times \text { RI18430-46, and Deylamani } \times \text { RI18430- } \\
46 \text { crosses were the best for increasing and decreasing SV, respectively. The high estimates of broad } \\
\text { sense heritability and narrow sense heritability for BV and FV, indicated the importance of additive } \\
\text { effects in expression of these traits. Therefore, selection base breeding methods will be useful to } \\
\text { improve these traits and selection in the early generations could be done to fix the favourable genes. } \\
\text { Low estimate of narrow sense heritability for SV revealed that non-additive gene effects play } \\
\text { important role in controlling setback viscosity. So, hybrid base breeding methods will be useful to } \\
\text { improve this trait. }\end{array}$ \\
\hline
\end{tabular}

\section{Introduction}

Rice (Oryza sativa L.) is the most important and extensively cultivated cereal crop stand next to wheat in the global food grain production and is the main source of livelihood for more than 1.50 million rural households (Roy et al., 2013). It provides the main staple food for more people in the world than any other crop (Feng et al., 2013). Rice productivity has greatly improved over the past few decades. However, new varieties need to be developed with much higher yields to cope with increasing population levels, but potential new varieties need to be accepted by farmers, the market, and consumers (Stuart et al., 2016).

Grain quality is one of the most important objectives of most rice breeding programs. In many rice-producing areas of the world, cooking and eating quality always represents a major criterion in evaluating rice grain. Cooking and eating quality in rice is mainly determined by the starch composition (Wang et al., 2010). Among various physicochemical properties, cooking properties are the mainly traits, determining the application quality of rice. Meanwhile, those properties have high heritability, supporting early selection for breeding to efficient to get the desired target trait (Chen et al., 2014). Starch is the major component of rice and described its physiochemical properties, such as gel strength and pasting properties (Singh et al., 2000; Martin and Fitzgerald, 2002; Derycke et al., 2005). The gelatinization and retrogradation properties of starch or flour are the most important properties of raw and cooking rice (Huang and Lai, 2014). Extensive studies have been undertaken to determine the quality of rice and starch-based foods, and new tools have been developed.

Currently, Rapid Visco Analyser (RVA) is seen as a rapid and reproducible analytical tool that can be used to assess the gelatinization and retrogradation properties of rice starch and flour during the heating and cooling cooking cycles (Fitzgerald et al., 2003). Effective 
information can be obtained from the RVA profile. The formation of a viscosity profile involves the transition from semi-crystalline power suspensions to a gelatinized paste (Zhou et al., 2016). The starch granules of rice play active role; if there is less swelling of starch during gelatinization, the peak viscosity of starch paste will be lower (Tananuwong and Malila, 2011). To understand the viscosity properties of rice starch, the RVA works as a physical index for the estimation and as a precursor of cooking and processing qualities (Martin and Fitzgerald, 2002; Bryant et al., 2012). Among the different RVA profiles, setback and breakdown values play significant role as compared to peak viscosity and others in the estimation of cooking quality of rice starch properties. The characteristic of RVA is closely connected to taste quality of rice, where higher peak viscosity and breakdown and the smaller setback value enhance the grain quality. The rice cooked is soft and glutinous in texture (Sharifi et al., 2009). The amount of amylose content in starch is positively correlated with rate and extent of retrogradation (Swinkels, 1998). Study showed that cooked rice with higher amylose rice starch varieties had lesser stickiness, cooked dry, while, keeping higher setback values or cultivars with lower breakdown value, peak viscosity and taste meter values fall in the category of inferior qualities rice variety (Kurasawa et al., 1972). Therefore, understanding the inheritance, specifically gene action, for rice appearance quality traits is desirable.

Diallel analysis is the first step in most plant breeding programs aimed at improving yield and other related parameters (Griffing, 1956). The diallel cross designs are frequently used in plant breeding research to obtain information about genetic properties of parental lines or estimates of general combining ability (GCA), specific combining ability (SCA) and heritability. The knowledge of combining ability is useful to assess nicking ability among genotypes and at the same time explicate the nature and magnitude of gene actions involved (Haghighi Hasanalideh et al., 2017). It also provides information on the additive and dominance variance which may be useful for suggesting an appropriate breeding strategy to be followed for isolation of pure lines or exploitation of heterosis. Based on combining ability analysis of different characters, higher SCA values refer to dominance gene effects and higher GCA effects indicate a greater role of additive gene effects controlling the characters. If both the GCA and SCA values are not significant, epistatic gene effects may play an important role in the genetic of characters (Sprague and Tatum, 1942). It is usually difficult to obtain sufficient $F_{1}$ seeds crops where hand emasculation must be done. Due to easiness of production of large quantity of $F_{2}$ seeds, many researchers use $F_{2}$ generation for diallel analysis to estimate combining ability and other genetic parameters, they also reported that $F_{2}$ analysis provide reliable and better information than $F_{1}$ generation (Hahghighi Hasanalideh et al., 2017).

Jin-Song et al. (2006) reported that the total main genetic variances accounted for over $64 \%$ of the total genetic variance for breakdown viscosity, consistency, and setback, indicating that these traits were mainly controlled by the main genetic effects in addition to the genotype environment interaction effects. The estimated total narrow-sense heritability was $67.8 \%, 79.5 \%$, and $79.5 \%$ for breakdown, consistency, and setback respectively. The general heritability accounted for over $75 \%$ of the total heritability, indicating that early selection would be effective for those traits.

Jin et al. (2004) analyzed taste meter value and Starch RVA properties by Griffing's diallel method with eight indica rice cultivars. They revealed that the additive variation was principal in taste meter value, peak viscosity, trough viscosity, final viscosity, breakdown, setback, consistency, while the non-additive variation was dominant in pasting temperature. the higher the taste meter value and RVA properties of parents, the greater the GCA effect in progeny population. The correlation coefficient between plot means in taste meter value and RVA properties and the GCA effect were significantly positive at the 0.01 level, therefore, it will be possible to be used in the forecast of taste meter value and RVA properties for the hybrid of rice.

Considering the above contents, the present study was undertaken to assess the combining ability of 6 rice varieties, for viscosity parameters and determining gene action controlling RVA characters with the aim of recognition breeding methods for improving quality traits of rice.

\section{Materials and Methods}

The plant material consisted of six parent diallel cross excluding reciprocals. The experiment was conducted at Rice Research Institute of Iran (RRII), Rasht, Guilan province, during 2012-2015. Six Iranian and foreign rice varieties (Table 1) were selected as parental lines in this study. These parents had differences in origin, pedigree and some of the quality and morphological traits (Table 1). Parent lines selected among 94 rice genotypes from different regions and origins thorough molecular analyzing for genetic diversity (Allahgholipour et al., 2014). These parental lines crossed in a diallel mating design in 2013. In order to produce $F_{2}$ progenies, $F_{1}$ populations from a $6 \times 6$ half diallel cross selfed in 2014. The plant genetic materials (parents and $\mathrm{F}_{2} \mathrm{~s}$ ) were grown in a randomized complete block design with three replications in research farm of Rice Research Institute of Iran (RRII) in 2015. After processing paddy to white rice, the samples were floured with a UD milling machine at a rate of 100 mesh. The rice flour samples (3g, based on $14 \%$ moisture) were mixed with distilled water $(25 \mathrm{ml})$ in an aluminum vessel. The pasting properties were measured by an RVA (RVA-3D model, Newport Scientific, Sydney, Australia). A rice standard profile was used and the heating and cooling cycle was as follows: the starting temperature was $50^{\circ} \mathrm{C}$, which was held for $1 \mathrm{~min}$, then the sample was heated through linear increasing of temperature to $95^{\circ} \mathrm{C}$ in $4 \mathrm{~min} 48 \mathrm{sec}$ and this was maintained for $7 \mathrm{~min} 18 \mathrm{sec}$ Finally the sample was cooled to $50^{\circ} \mathrm{C}$ (linear decreasing in temperature for $11 \mathrm{~min} 6 \mathrm{sec}$ ), which was held for $12 \mathrm{~min}$. The device was set to start at $960 \mathrm{rpm}$ in the first $10 \mathrm{secs}$, and after, the speed was set at $160 \mathrm{rpm}$. (American Association of Cereal Chemists, 1995). Then starch RVA parameters including Peak Viscosity (PV), Breakdown Viscosity (BV), Final Viscosity (FV) and Setback Viscosity (SV) were evaluated. 
Table 1 Name, origin and pedigree of rice genotypes used in this study

\begin{tabular}{|c|c|c|c|}
\hline S.N & Genotypes & Pedigree & Origin \\
\hline 1 & Gilaneh $^{\mathrm{a}}$ & Saleh $^{\mathrm{a}} /$ Abjiboji $^{\mathrm{b}} / /$ Abjiboji & RRII $^{\mathrm{c}}$, Iran \\
\hline 2 & Daylamani & Local cultivar & Mazandran, Iran \\
\hline 3 & IR50 & IR50 & IRRI $^{\mathrm{d}}$, Philippines \\
\hline 4 & Line 23 & IR75479-199-3-3 & IRRI, Philippines \\
\hline 5 & RI18447-2 & Sepidrood $^{\mathrm{a}} /$ Gharib $^{\mathrm{b}}$ & RRII, Iran \\
\hline 6 & RI18430-46 & Saleh $^{\text {a } / \text { Hashemi }}{ }^{\mathrm{b}}$ & RRII, Iran \\
\hline
\end{tabular}

${ }^{a}$ Improved rice variety of Iran, ${ }^{b}$ Local rice variety of Iran, ${ }^{\mathrm{c}}$ Rice Research Institute of Iran, ${ }^{\mathrm{d}}$ International Rice Research

Table 2 Analysis of variance for RVA parameters.

\begin{tabular}{l|ccccc}
\hline \multirow{2}{*}{ Source of variance } & \multirow{2}{*}{ df } & \multicolumn{4}{c}{ Mean Square } \\
\cline { 2 - 6 } & & $\mathrm{PV}$ & $\mathrm{BV}$ & $\mathrm{FV}$ & $110.96^{* *}$ \\
Genotypes & 20 & $1328.16^{* *}$ & $514.25^{* *}$ & $1524.84^{* *}$ & $9.10^{\text {ns }}$ \\
Replications & 2 & $12.29^{\text {ns }}$ & $0.32^{\text {ns }}$ & $9.65^{\text {ns }}$ & 20.24 \\
Error & 40 & 72.77 & 29.20 & 84.96 & 24 \\
ns and ** non-significant and significant at 1\% probability level respectively, PV= Peak Viscosity, BV= Breakdown Viscosity, FV= Final Viscosity and \\
SV= Setback Viscosity.
\end{tabular}

Table 3 Analysis of variance for combining ability

\begin{tabular}{|c|c|c|c|c|c|}
\hline \multirow{2}{*}{ Source of variance } & \multirow{2}{*}{ df } & \multicolumn{4}{|c|}{ Mean Square } \\
\hline & & PV & $\mathrm{BV}$ & $\mathrm{FV}$ & SV \\
\hline Replication & 2 & $13.24^{\mathrm{ns}}$ & $4.14^{\mathrm{ns}}$ & $20.86^{\mathrm{ns}}$ & $1.99^{\text {ns }}$ \\
\hline GCA & 5 & $1482.45^{* *}$ & $628.32 * *$ & $1969.9 * *$ & $85.87 * *$ \\
\hline SCA & 15 & $486.27 * *$ & $143.36^{* *}$ & $616.49 * *$ & $141.25^{* *}$ \\
\hline Error & 40 & 90.39 & 36.43 & 104.01 & 18.97 \\
\hline Baker Ratio & & 0.86 & 0.89 & 0.86 & 0.55 \\
\hline
\end{tabular}

Analysis of variance was performed by MSTATC ver 1.42 (ANOVA) and Griffing's (1956) diallel analysis was conducted by Dial 98 software (Ukai, 2006) to estimate the general (GCA) and specific (SCA) combining abilities determined according to Singh and Chaudary (1977). This method was calculated by following model:

$$
X_{i j}=u+g_{i}+g_{j}+s_{i j}+e_{i j k}
$$

Where, $\mathrm{u}=$ the population mean, $\mathrm{g}_{\mathrm{i}}=$ the general combining ability effect of the $i^{\text {th }}$ parent, $g_{j}=$ the general combining ability effect of the $\mathrm{j}^{\text {th }}$ parent, $\mathrm{s}_{\mathrm{ij}}=$ the specific combining ability effect of the cross between $i^{\text {th }}$ and $j^{\text {th }}$ parents such that $\mathrm{s}_{\mathrm{ij}}=\mathrm{s}_{\mathrm{ji}}$ and $\mathrm{e}_{\mathrm{ijk}}$ the environmental effect associated with $\mathrm{ijk}^{\text {th }}$ observation. The combining ability ratio was calculated according to Baker (1978) as follow:

Baker ratio $=\frac{2 \mathrm{MS}_{\mathrm{GCA}}}{2 \mathrm{MS}_{\mathrm{GCA}}+\mathrm{MS}_{\mathrm{SCA}}}$

$\mathrm{F}_{2}$ 's genetic parameters determined according to Dhellon and Malhi (1976) and Sharma (2006). Hayman's graph $\left(\mathrm{V}_{\mathrm{r}}-\mathrm{W}_{\mathrm{r}}\right.$ graph $)$ is drawn with the help of variances of arrays $\left(\mathrm{V}_{\mathrm{r}}\right)$ and covariance's $\left(\mathrm{W}_{\mathrm{r}}\right)$ between parents and their $F_{2}$ progenies. The array refers to the crosses in which a particular parent is common. The $\mathrm{W}_{\mathrm{ri}}$ values are estimated for all the arrays by the formula: $\mathrm{W}_{\mathrm{ri}}=\left(\mathrm{V}_{\mathrm{ri}} \times \mathrm{V}_{\mathrm{OLO}}\right)^{0.5}$ where, $\mathrm{V}_{\mathrm{ri}}$ is the variance of $\mathrm{r}^{\text {th }}$ array and $\mathrm{V}_{\mathrm{OLO}}$ is the variance of parents. The $\mathrm{W}_{\mathrm{ri}}$ values are plotted against $\mathrm{V}_{\mathrm{r}}$ values to draw the limiting parabola. The $\mathrm{W}_{\mathrm{ri}}$ values are obtained by the formula: $\mathrm{W}_{\mathrm{ri}}=\mathrm{W}_{\mathrm{r}}-\mathrm{bV}_{\mathrm{r}}+\mathrm{bV}_{\mathrm{ri}}$ for drawing regression line, where, $\mathrm{V}_{\mathrm{ri}}$ is array mean of variances, $\mathrm{W}_{\mathrm{r}}$ is array mean of covariance's and b is regression coefficient (Singh et al., 1990; Singh and Narayanan, 1993).

\section{Results}

Analysis of variance for RVA parameters revealed highly significant differences among genotypes (parents and hybrids) for all studied traits, showing the presence of genotypic variability among them (Table 2). The diallel analysis by Griffing`s method indicated highly significant differences of GCA and SCA variances for traits PV, BV, FV and SV (Table 3). Baker's ratio (Table 3) showed the amounts of $0.86,0.89,0.86$ and 0.55 for PV, BV, FV and $\mathrm{SV}$, respectively.

Estimate of GCA for RVA parameters of parents using in this study showed that for PV parameter, parents Gilaneh and IR50 had negative estimation of GCA, whereas other parents had positive estimate of GCA. Parent RI18447-2 had highest GCA and parent IR50 showed lowest amount of GCA. For BV, IR50 and Deylamani had the lowest and highest GCA, respectively. For FV, IR50 and RI18447-2 revealed the minimum and maximum estimation of GCA, respectively. Parents RI18430-46 and RI18447-2 had highest and lowest estimation of GCA, respectively, for SV parameter. The estimates of SCA for RVA parameters (Table 4) indicated that The Gilaneh $\times$ Daylamani and Gilaneh $\times$ RI18447-2 crosses had the highest and lowest SCA for PV and BV. For FV, the IR50 $\times$ Line 23 and Line $23 \times$ RI18447-2 crosses had the lowest and highest SCA, respectively. The Gilaneh $\times$ RI18430-46, had the highest SCA for SV, and the Deylamani $\times$ RI18430-46 cross had minimum amount of SCA estimation. 
Table 4 General combining ability (GCA) of rice genotypes for RVA parameters.

\begin{tabular}{l|cccc}
\hline \multirow{2}{*}{ Parents } & \multicolumn{4}{c}{ RVA parameters } \\
\cline { 2 - 5 } & PV & BV & FV & SV \\
\hline Gilaneh & -0.27 & 4.09 & 2.45 & 2.72 \\
Daylamani & 6.21 & 10.09 & 6.13 & -0.08 \\
IR50 & -21.57 & -10.03 & -24.27 & -2.71 \\
Line 23 & 5.13 & -2.51 & 5.3 & 0.16 \\
RI18447-2 & 9.28 & -5 & 12.48 & 3.2 \\
RI18430-46 & 1.21 & 3.36 & -2.08 & -3.29 \\
SE(gi) & 3.07 & 1.95 & 3.29 & 1.40 \\
\hline
\end{tabular}

PV= Peak Viscosity, BV= Breakdown Viscosity, FV= Final Viscosity and SV= Setback Viscosity.

Table 5. Specific combining ability (SCA) of crosses genotypes for RVA parameters.

\begin{tabular}{l|cccc}
\hline \multirow{2}{*}{ Crosses } & \multicolumn{4}{|c}{ RVA parameters } \\
\cline { 2 - 5 } & PV & BV & FV & SV \\
\hline $1 \times 2$ & 13.21 & 10.21 & 7.26 & -5.95 \\
$1 \times 3$ & 12.02 & 3.75 & 14.44 & 2.42 \\
$1 \times 4$ & 4.9 & 3.65 & -0.88 & -5.78 \\
$1 \times 5$ & -19.75 & -10.45 & -21.09 & -1.34 \\
$1 \times 6$ & -10.37 & -7.17 & 0.27 & 10.65 \\
$2 \times 3$ & -1.16 & -4.75 & 7.43 & 8.58 \\
$2 \times 4$ & -5.11 & -2.91 & 0.13 & 5.24 \\
$2 \times 5$ & 1.47 & -3.95 & 0.73 & -0.74 \\
$2 \times 6$ & -8.41 & 1.41 & -15.55 & -7.14 \\
$3 \times 4$ & -17.33 & -2.68 & -22.83 & -5.49 \\
$3 \times 5$ & 3.13 & 3.34 & 0.27 & -2.86 \\
$3 \times 6$ & 3.34 & 0.34 & 0.69 & -2.65 \\
$4 \times 5$ & 8.63 & 3.79 & 14.54 & 5.91 \\
$4 \times 6$ & 8.92 & -1.85 & 9.04 & 0.12 \\
$5 \times 6$ & 6.52 & 7.28 & 5.55 & -0.97 \\
$\mathrm{SE}\left(\mathrm{s}_{\mathrm{ij}}\right)$ & 8.43 & 5.35 & 9.04 & 3.86 \\
\hline
\end{tabular}

$\mathrm{PV}=$ Peak Viscosity, BV= Breakdown Viscosity, FV= Final Viscosity and SV= Setback Viscosity. 1=Gilaneh, 2=Deylamani, 3=IR50, 4=line 23, 5=RI18447-2, 6=RI18430-46.

Table 6 Estimation of genetic parameters for RVA parameters.

\begin{tabular}{|c|c|c|c|c|}
\hline \multirow{2}{*}{ Genetic Parameters } & \multicolumn{4}{|c|}{ RVA parameters } \\
\hline & PV & BV & $\mathrm{FV}$ & SV \\
\hline $\mathrm{D}$ & $932.95 * *$ & $378.27 * *$ & $911.06^{* *}$ & $19.29 *$ \\
\hline $\mathrm{H} 1$ & $1363.57 * *$ & $154.3 *$ & $1691.93 * *$ & $135.77 * *$ \\
\hline $\mathrm{H} 2$ & $870.59 * *$ & $128.7 *$ & $1099.6^{* *}$ & $123.92 * *$ \\
\hline $\mathrm{F}$ & $1042.78 * *$ & $155.3^{\mathrm{ns}}$ & $1070.65 * *$ & $14.23^{\mathrm{ns}}$ \\
\hline $0.25 \mathrm{sqr}(\mathrm{H} 1 / \mathrm{D})$ & $1.21 * *$ & $0.32 * *$ & $1.36 * *$ & $1.33^{\text {ns }}$ \\
\hline $\mathrm{kd} /(\mathrm{kd}+\mathrm{kr})$ & $0.73 * *$ & $0.66^{* *}$ & $0.72 * *$ & $0.57 * *$ \\
\hline uv & $0.16^{* *}$ & $0.21 * *$ & $0.16^{* *}$ & $0.23 * *$ \\
\hline$h_{b}^{2}$ & $0.94 * *$ & $0.94 * *$ & $0.94 * *$ & $0.86 * *$ \\
\hline $\mathrm{h}^{2}{ }_{\mathrm{n}}$ & $0.44 * *$ & $0.75^{* *}$ & $0.61 * *$ & $0.18 *$ \\
\hline
\end{tabular}

${ }_{\mathrm{ns}}, *$ and $* *$ non-significant and significant at $5 \%$ and $1 \%$ probability levels respectively, PV= Peak Viscosity, BV= Breakdown Viscosity, FV= Final Viscosity and $\mathrm{SV}=$ Setback Viscosity, $\mathrm{D}=$ Additive variance, $\mathrm{H} 1=$ Dominance variance, $\mathrm{H} 2=$ Dominance variance, $\mathrm{F}=$ Relative frequency of dominant and recessive allels, $0.25 \mathrm{sqr}(\mathrm{H} 1 / \mathrm{D})=$ Average degree of dominance, $(\mathrm{kd} / \mathrm{kd}+\mathrm{kr})=$ Proportion of dominance genes, uv= Balance of positive and negative alleles, $\left(\mathrm{h}^{2} \mathrm{~b}\right)=$ Broad-sense heritability, $\left(\mathrm{h}_{\mathrm{n}}{ }^{\mathrm{n}}\right)=$ Narrow-sense heritability.

Estimates of genetic parameters (Table 6) revealed that the parameters D, H1 and $\mathrm{H} 2$ were significant for all RVA parameters. Average degree of dominance (0.25sqr(H1/D)) was significant and lesser than one for BV. While, it was greater than one for PV, FV and SV. Although, the average degree of dominance was not significant for SV. Broad sense heritability $\left(\mathrm{h}^{2}{ }_{\mathrm{b}}\right)$ had high estimations for all RVA parameters. Narrow sense heritability $\left(h^{2}\right)$ estimates was moderate for $\mathrm{FV}$, high for $\mathrm{PV}$ and $\mathrm{BV}$ and low for $\mathrm{SV}$.

Hayman's graphs revealed that regression line passed below the origin cutting $\mathrm{W}_{\mathrm{r}}$ axis in the negative region for PV, FV and SV (Figure 1, 3 and 4 respectively). showing the presence of over dominance. However, high difference between regression line and regression line with slope of one for SV, suggested the presence of non-allelic interaction. Hayman's graph for BV (Figure 2) revealed the presence of partial dominance of gene effect due to passing regression line above the origin. The dispersion of parents around the regression line for PV and FV (Figure 1 and 3) indicated that parents Gilaneh, Deylamani, IR50, RI184472 and RI18430-46 were close to the origin of the coordinate, and accordingly had more than $75 \%$ dominant genes, while, parents Line 23 was far from the origin, therefore it had $<25 \%$ of dominant genes. The dispersion 
of parents around the regression line for BV (Figure 2) showed that parents IR50 and RI18447-2 were close to the origin of the coordinate, and accordingly have more than $75 \%$ of dominant genes parents Gilaneh, Line 23 and RI18430-46 had 50-75\% of dominant genes, while parent

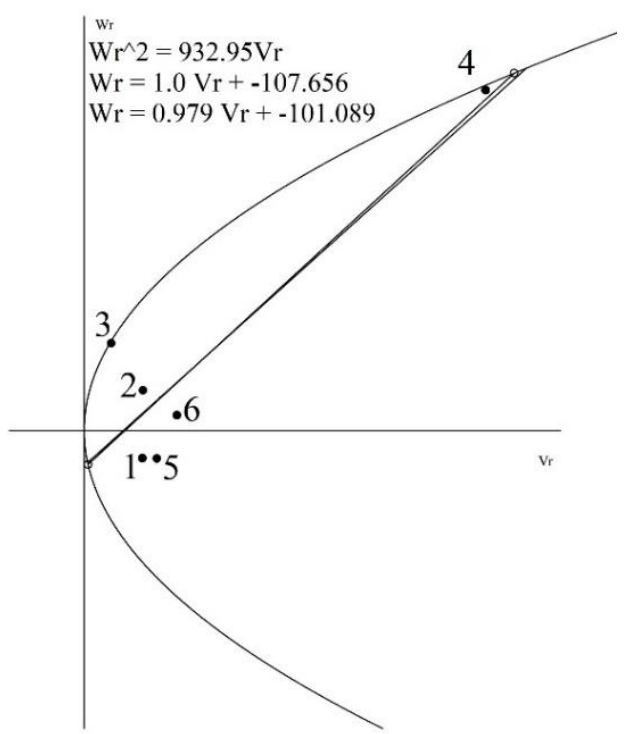

Figure 1 Regression line and dispersion of parents around origin for Peak Viscosity. 1=Gilaneh, 2=Deylamani, 3=IR50, 4=line 23, 5=RI18447-2, 6=RI18430-46.

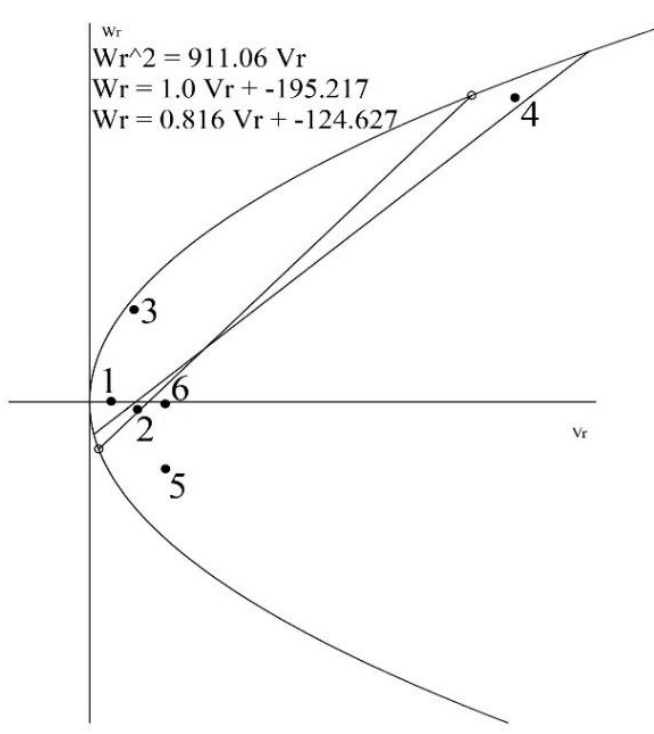

Figure 3 Regression line and dispersion of parents around origin for Final Viscosity. 1=Gilaneh, 2=Deylamani, 3=IR50, 4=line 23, 5=RI18447-2, 6=RI18430-46.

\section{Discussion}

The results of combining ability analysis indicated that GCA and SCA variances were significant for all RVA parameters, indicating the involvement of additive and non-additive effects of gene action in their inheritance, however high amounts of Bakers ratio for PV, BV and FV remarked more portion of additive gene effect in controlling these traits. Jin et al. (2004) reported that additive gene effect was principal in PV, FV, BV and SV. Gravois and Webb (1997) reported the presence of additive effects because of significant GCA for peak, hot paste, and cool paste viscosities.
Deylamani was far from the origin and therefore had lesser than $25 \%$ of dominant genes. Most of the dominant genes for SV (Figure 4) were distributed in parents Gilaneh, and RI18447-2, while, recessive genes were mostly distributed in parent RI18430-46.

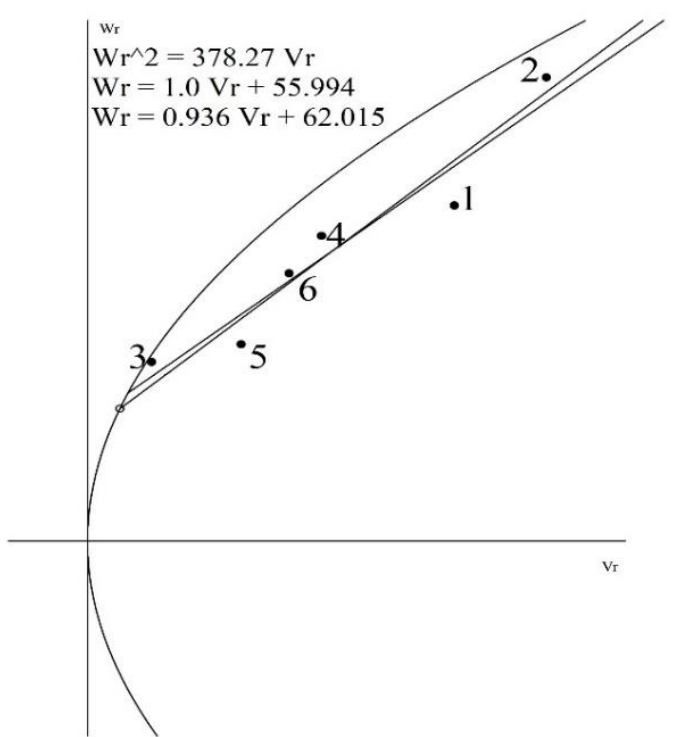

Figure 2 Regression line and dispersion of parents around origin for Breakdown Viscosity. 1=Gilaneh, 2=Deylamani, 3=IR50, 4=line 23, 5=RI18447-2, 6=RI18430-46.

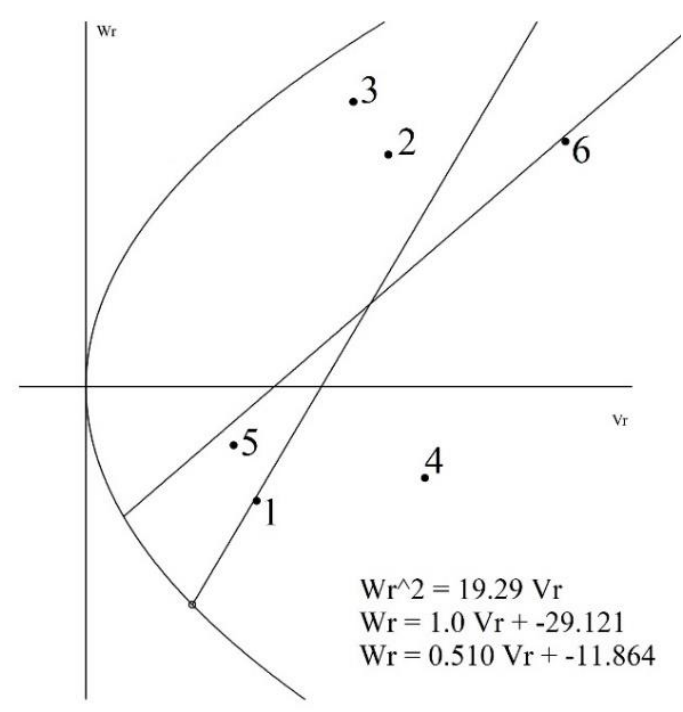

Figure 4 Regression line and dispersion of parents around origin for Setback Viscosity. 1=Gilaneh, 2=Deylamani, 3=IR50, 4=line 23, 5=RI18447-2, 6=RI18430-46.

Due to high estimates of Baker's ratio and likewise, more portion of additive gene action in controlling traits PV, BV and FV, according to GCA estimates, for PV and FV, parents IR50 and RI18447-2 were the best combiners for increasing and decreasing, respectively. Parents IR50 and Deylamani were the best combiners for increasing and decreasing $\mathrm{BV}$, respectively. Beside, due to more portion of non-additive gene action in controlling trait SV, The Gilaneh $\times$ RI18430-46, and Deylamani $\times$ RI18430-46 crosses were the best combines for increasing and decreasing SV, respectively. 
Estimation of genetic parameters for RVA characters showed that the additive and dominance variances was significant for all RVA parameters, indicating that there was additive and non-additive effect of gene action in genetic controlling of these traits. For PV and FV, significant amount of parameter $\mathrm{H} 2$ and deviation from 0.25 of parameter uv (Balance of positive and negative alleles) showed that the distribution of alleles in parents was not uniform. Estimation of $\mathrm{H} 1$ parameter was greater than estimation of parameter $\mathrm{H} 2$, for all studied traits. So, most of the genes in the parent for these traits are genes with positive effects. Estimates of parameter $F$ were greater than zero for all RVA parameters. Therefore, the ratio of dominant alleles is greater than the recessive alleles for these traits. It confirmed due to greater than 0.5 estimation values of Proportion of dominance genes $(\mathrm{kd} /(\mathrm{kd}+\mathrm{kr}))$. The average degree of dominance was greater than one for PV, $\mathrm{FV}$ and $\mathrm{SV}$, and revealed the existence of over dominance phenomenon in these traits. Whereas, partial dominance phenomenon indicated for $\mathrm{BV}$ due to lesser than one estimate of average degree of dominance. The high estimates of broad sense heritability and narrow sense heritability for $\mathrm{BV}$ and $\mathrm{FV}$, indicated the importance of additive effects in expression of these traits. Therefore, selection base breeding methods will be useful to improve these traits and selection in the early generations could be done to fix the favorable genes. Low estimate of narrow sense heritability for SV, revealed that non-additive gene effects play important role in controlling this trait. So, hybrid base breeding methods will be useful to improve this trait. These results are in agree with results reported by Jin-Song et al. (2006). Also, Allahgholipour and Rabiei (2017) reported that additive gene effects play important role in controlling PV and BV, whereas non-additive gene effects are the principle players in controlling FV and SV. Allahgholipour et al. (2012) reported greater additive variance in compared to dominance variance for $\mathrm{FV}, \mathrm{PV}$, $\mathrm{BV}$ and SV, suggesting the uses of selection base breeding methods for improving these traits.

\section{References}

Allahgholipour M, Rabiei B. 2017. Identification of heterotic combinations for paste viscosity properties of rice grain using GGE biplot method. Cereal Research, 6(3): 367-383.

Allahgholipour M, Rabiei B, Yekta M. 2012. Assessment of general and specific combining abilities of the starch paste viscosity properties in parental lines of hybrid rice. Iranian Journal of Crop Sciences, 13(1) :178-193.

Allahgholipour M, Farshadfar E, Rabiei B. 2014. Molecular characterization and genetic diversity analysis of different rice cultivars by microsatellite markers. Genetika, 46(1): 187 198.

American Association of Cereal Chemists (AACC). 1995. Determination of the pasting properties of rice with the Rapid Visco Analyser. AACC method 61-02. First approval. 10-2694. Approved Method of Analysis. 9th Editon Amer. Assoc. real. Chem. St. Paul. MN.

Baker RJ. 1978. Issues in diallel analysis. Crop Science, 18: 533 536.

Bryant RJ, Anders M, Mcclung A. 2012. Impact of production practices on physicochemical properties of rice grain quality. Journal of the Science of Food and Agriculture, 92(3): 564569.
Chen X, Cui Z, Fan M, Vitousek P, Zhao M, Ma W, ... Deng X. 2014. Producing more grain with lower environmental costs. Nature, 514(7523): 486.

Derycke V, Veraverbeke WS, Vandeputte GE, De Man W, Hoseney RC, Delcour JA. 2005. Impact of proteins on pasting and cooking properties of nonparboiled and parboiled rice. Cereal Chemistry, 82(4): 468-474.

Dhillon BS, Malhi SS. 1976. a note on hayman's diallel analysis of $\mathrm{F}_{2}$ generation, Canadian Journal of Genetics and Cytology, 18(3): 549-550.

Feng X, Zhang Q, Cong P, Zhu Z. 2013. Preliminary study on classification of rice and detection of paraffin in the adulterated samples by Raman spectroscopy combined with multivariate analysis. Talanta, 115: 548-555.

Fitzgerald MA, Martin M, Ward RM, Park WD, Shead HJ. 2003. Viscosity of rice flour: A rheological and biological study. Journal of Agricultural and Food Chemistry, 51(8): 22952299.

Gravois KA, Webb BD. 1997. Inheritance of long grain rice amylograph viscosity characteristics. Euphytica, 97(1): 2529.

Griffing B. 1956. A generalized treatment of use of diallel crosses in quantitative inheritance. Heredity, 10: 31-50.

Haghighi Hasanalideh A, Farshadfar E, Allahgholipour M. 2017. Genetic parameters and combining ability of some important traits in rice (Oryza sativa L.). Genetika, 49(3): 1001-1014.

Huang YC, Lai HM. 2014. Characteristics of the starch fine structure and pasting properties of waxy rice during storage. Food Chemistry, 152: 432-439.

Jin Z, Jiang W, Chin J, Koh H. 2004. Analysis on the combining ability of taste meter value and starch RVA properties in Indica rice. Zuo Wu Xue Bao, 30(12): 1210-1214.

Jin-Song BAO, Sheng-Quan SHEN, Ying-Wu XIA. 2006. Analysis of genotype $\times$ environment interaction effects for starch pasting viscosity characteristics in indica rice. Acta Genetica Sinica, 33(11): 1007-1013.

Kurasawa H, Kanauti Y, Takei K, Ogawa S, Okabe T, Hayakawa T, Igaue I. 1972. Correlation analysis between eating quality, rheological property and amylose content of starch. Agricultural and Biological Chemistry, 36(10): 1809-1813.

Martin M, Fitzgerald MA. 2002. Proteins in rice grains influence cooking properties!. Journal of Cereal Science, 36(3): 285294.

Roy B, Surje DT, Mahato S. 2013. Biodiversity of farmers' varieties of rice (Oryza sativa L.) at repository of Uttar Banga Krishi Viswavidyalaya: a reservoir of important characters. The Ecoscan, 4: 145-151.

Sharifi P, Dehghani H, Mumeni A, Moghaddam M. 2009. Genetic and genotype $\times$ environment interaction effects for appearance quality of rice. Agricultural Sciences in China, 8(8), 891-901.

Sharma JR. 2006. Statistical and biometrical techniques in plant breeding. New Age International. pp. 433.

Singh M, Srivastava JP, Kumar ARVIND. 1990. Effect of water stress on water potential components in wheat genotypes. Indian Journal of Plant Physiology, 33: 312-317.

Singh P, Narayanan SS. 1993. Biometrical techniques in plant breeding. 1st Edn Kalayani publishers, New Delhi, India.

Singh RK, Chaudhary BD. 1977. Diallel analysis. In: Biometrical methods in quantitative genetic analyses. Ludhiana, India.

Singh V, Okadome H, Toyoshima H, Isobe S, Ohtsubo KI. 2000. Thermal and physicochemical properties of rice grain, flour and starch. Journal of Agricultural and Food Chemistry, 48(7): 2639-2647.

Sprague GF, Tatum LA. 1942. General versus specific combining ability in single crosses of corn. Agronomy Journal, 34: 923932. 
Stuart AM, Pame ARP, Silva JV, Dikitanan RC, Rutsaert P, Malabayabas AJB, Singleton GR. 2016. Yield gaps in ricebased farming systems: insights from local studies and prospects for future analysis. Field Crops Research, 194: 4356.

Swinkels JJM. 1998. Industrial starch chemistry. AVEBE Brochure, The Netherlands.

Tananuwong K, Malila Y. 2011. Changes in physicochemical properties of organic hulled rice during storage under different conditions. Food Chemistry, 125(1): 179-185.
Ukai Y. 2006. DIAL98. A package of programs for the analyses of a full and half diallel table with the methods by Hayman (1954), Griffing (1954) and others. Available from: http://lbm.ab.a.u-okyo.ac.jp/ ukai/dial98.html.

Wang XQ, Yin LQ, Shen GZ, Li X, Liu QQ. 2010. Determination of amylose content and its relationship with RVA profile within genetically similar cultivars of rice (Oryza sativa L. ssp. japonica). Agricultural Sciences in China, 9(8): 11011107.

Zhou Z, Yang X, Su Z, Bu D. 2016. Effect of ageing-induced changes in rice physicochemical properties on digestion behavior following storage. Journal of Stored Products Research, 67: 13-18. 